\title{
PERBANDINGAN KEEFISIENAN METODE NEWTON-RAPHSON, METODE SECANT, DAN METODE BISECTION DALAM MENGESTIMASI IMPLIED VOLATILITIES SAHAM
}

\author{
Ida Ayu Ega Rahayuni ${ }^{\S 1}$, Komang Dharmawan ${ }^{2}$, Luh Putu Ida Harini ${ }^{3}$ \\ ${ }^{1}$ Jurusan Matematika, Fakultas MIPA - Universitas Udayana [Email: egaidaayu@gmail.com] \\ ${ }^{2}$ Jurusan Matematika, Fakultas MIPA - Universitas Udayana [Email: dharmawan.komang@gmail.com] \\ ${ }^{3}$ Jurusan Matematika, Fakultas MIPA - Universitas Udayana [Email: ballidah@gmail.com] \\ ${ }^{\S}$ Corresponding Author
}

\begin{abstract}
Black-Scholes model suggests that volatility is constant or fixed during the life time of the option certainly known. However, this does not fit with what happen in the real market. Therefore, the volatility has to be estimated. Implied Volatility is the etimated volatility from a market mechanism that is considered as a reasonable way to assess the volatility's value. This study was aimed to compare the Newton-Raphson, Secant, and Bisection method, in estimating the stock volatility value of PT Telkom Indonesia Tbk (TLK). It found that the three methods have the same Implied Volatilities, where Newton-Raphson method gained roots more rapidly than the two others, and it has the smallest relative error greater than Secant and Bisection methods.
\end{abstract}

Keywords: Black-Scholes, Implied Volatility, Newton-Raphson Method, Secant Method, Bisection Method

\section{PENDAHULUAN}

Salah satu alternatif instrumen investasi yang dapat ditawarkan kepada investor didalam pasar modal adalah opsi (option). Pada tahun 1973, model Black-Scholes dikembangkan oleh Myron Scholes dan Fischer Black. Model ini memberikan solusi untuk penilaian call option dan put option yang tidak memberikan dividen. Pada model Black-Scholes, volatilitas bersifat konstan atau tetap selama usia opsi diketahui pasti. Namun, hal ini tidak sesuai dengan apa yang terjadi pada pasar sebenarnya. Oleh karena volatilitas bergerak secara random dan tidak dapat diobservasi secara langsung, maka harus dilakukan penaksiran nilai volatilitas (Dharmawan \& Widana [2]). Nilai volatilitas dapat ditaksir menggunakan Implied Volatility. Implied Volatility adalah volatilitas yang diestimasi dari mekanisme pasar dengan memilih kontrak opsi dengan expiration date yang sama. Berdasarkan keadaan persaingan pasar, Black dan Scholes menunjukkan bahwa harga saham mengikuti gerak Brown geometrik pada suku bunga dan volatilitas tertentu. Pergerakan harga saham tersebut dapat ditulis dalam bentuk sebagai berikut

dengan

$$
d S_{t}=\mu S_{t} d t+\sigma S_{t} d W_{t}
$$

$d S_{t}$ : perubahan harga saham yang mengikuti gerak Brown geometric

$\mu \quad$ : rata-rata dari pengembalian saham

$d t \quad$ : perubahan waktu

$\sigma \quad:$ nilai volatilitas

$W_{t}$ : gerak Brownian

Menurut Lee [3], keadaan pasar yang demikian dikatakan tidak ada arbitrase. Dengan kata lain, pelaku pasar modal mengasumsikan bahwa harga opsi di pasar modal sama dengan harga teoritis yang dihitung menggunakan formula Black-Scholes, atau dapat ditulis sebagai

$$
C_{o b s}=C_{B S}(\sigma)
$$

dengan $C_{o b s}$ menyatakan harga opsi observasi yang diperoleh dari harga pasar sebenarnya, 
dimana strike price $(K)$ dan masa jatuh tempo opsi ( $T$ ) sama dengan $K$ dan $T$ saham induk. Dalam hal ini, $C_{B S}$ menyatakan harga opsi teoritis dari formula Black-Scholes yang didefinisikan oleh:

$$
C_{B S}=S_{t} N\left(d_{1}\right)-K e^{-r(T-t)} N\left(d_{2}\right)
$$

dengan

$$
\begin{aligned}
& d_{1}=\frac{\ln \left(\frac{S_{t}}{K}\right)+\left(r+\frac{1}{2} \sigma^{2}\right)(T-t)}{\sigma \sqrt{T-t}} \\
& d_{2}=d_{1}-\sigma \sqrt{T}
\end{aligned}
$$

dengan $N\left(d_{i}\right)$ adalah fungsi distribusi normal kumulatif standar.

Nilai volatilitas selalu positif karena $C_{B S}$ adalah konstan dan $C_{o b s}$ monoton naik pada $[0, \infty)$ (Dharmawan \& Widana [2]).

Pada penelitian ini, solusi dari volatilitas akan diselesaikan menggunakan metode Newton-Raphson, metode Secant dan metode Bagi Dua (Bisection). Penurunan rumus metode Newton Raphson dapat dilakukan secara geometris dan dengan bantuan deret Taylor. Jika $x_{i-1}$ adalah hampiran saat ini, maka hampiran selanjutnya adalah $x_{i}$ yang dapat ditulis sebagai berikut.

$$
x_{i}=x_{i-1}-\frac{f\left(x_{i-1}\right)}{f^{\prime}\left(x_{i-1}\right)}, f^{\prime}\left(x_{i-1}\right) \neq 0
$$

sampai $\left|e_{r}\right|<e_{t o l}$, dengan

$$
\left|e_{r}\right|=\left|\frac{x_{i}-x_{i-1}}{x_{i}}\right|, x_{i} \neq 0
$$

dan $e_{t o l}=10^{-5}$.

Metode Secant merupakan modifikasi dari metode Newton-Raphson, yaitu dengan mengganti fungsi turunan yang digunakan pada metode Newton-Raphson menjadi bentuk lain yang ekuivalen. Metode ini dimulai dengan hampiran awal $x_{i-1}$ dan $x_{i}$ untuk solusi $x$. Selanjutnya dihitung $x_{i+1}$ sebagai hampiran baru untuk $\sigma$, yaitu

$$
x_{i+1}=x_{i}-\frac{f\left(x_{i}\right)\left(x_{i}-x_{i-1}\right)}{f\left(x_{i}\right)-f\left(x_{i-1}\right)}
$$

sampai $\left|e_{r}\right|<e_{\text {tol }}$.
Metode Bagi Dua (Bisection) dimulai dengan sebuah interval $\left[x_{i-1}, x_{i}\right]$, dimana $f\left(x_{i-1}\right)$ dan $f\left(x_{i}\right)$ berbeda tanda (Mathews [4]). Secara sistematis metode Bisection adalah metode pencarian akar dengan mengurangi separuh interval pertama untuk memilih titik

$$
x_{i+1}=\frac{x_{i-1}+x_{i}}{2}
$$

dan kemudian menganalisa kemungkinan yang akan timbul:

(i) Jika $f\left(x_{i-1}\right)$ dan $f\left(x_{i+1}\right)$ berbeda tanda, akar terletak di $\left[x_{i-1}, x_{i+1}\right]$

(ii) Jika $f\left(x_{i+1}\right)$ dan $f\left(x_{i}\right)$ berbeda tanda, akar terletak di $\left[x_{i+1}, x_{i}\right]$

(iii) Jika $f\left(x_{i+1}\right)=0$, diperoleh bahwa akar pada $x=x_{i+1}$

Jika salah satu dari kasus (i) atau kasus (ii) terjadi, diperoleh interval yang merupakan setengah bagian dari interval pertama yang mengurung akar dan mengurangi separuh interval tersebut dengan proses yang sama. Pada proses selanjutnya, separuh interval baru tersebut dinamai $\left[x_{i-1}, x_{i}\right]$ dan proses diulang sampai $\left|e_{r}\right|<e_{t o l}$. Jika kasus (iii) terjadi, maka akar adalah $x_{i+1}$.

Selanjutnya membandingkan perhitungan antara metode Newton-Raphson, metode Secant, dan metode Bisection dalam mengestimasi nilai volatilitas saham.

\section{METODE PENELITIAN}

\section{A. Jenis dan Sumber Data}

Jenis data yang digunakan pada penelitian ini adalah data sekunder yang berupa data numerik. Adapun data yang digunakan terdiri dari strike price, dan harga saham sekarang (15 Mei 2015) dari saham PT Telekomunikasi Indonesia Tbk (TLK) dengan masa jatuh tempo opsi selama tiga bulan yang diperoleh dari http://finance.yahoo.com, data harga observasi call option diperoleh dari http://optiondata.net. 


\section{B. Algoritma untuk Menaksir Implied Volatility}

Tahapan-tahapan yang dilakukan pada penelitian ini adalah sebagai berikut:

1. Mencari harga observasi call option $\left(C_{o b s}\right)$ yang memiliki masa jatuh tempo dan strike price yang sama dengan saham induk, serta mencari harga saham sekarang dari underlying asset.

2. Menentukan fungsi volatilitas dan mencari turunan pertamanya.

3. Menyelesaikan persamaan dari fungsi volatilitas menggunakan metode numerik, yakni metode Newton-Raphson, metode Secant, dan metode Bisection.

\section{a.Penyelesaian Menggunakan Metode Newton-Raphson}

Langkah 1: Tetapkan hampiran awal $\left(\sigma_{i-1}\right), e_{t o l}=10^{-5}$, iterasi maksimum $\quad\left(\max _{-} i t e r\right)=$ 100

Langkah 2: Menghitung nilai $f\left(\sigma_{i-1}\right)$ dan turunan pertama fungsinya $f^{\prime}\left(\sigma_{i-1}\right)$

Langkah 3: Menentukan nilai hampiran kedua $\left(\sigma_{i}\right)$ yang terletak pada perpotongan garis singgung di $\left(\sigma_{i-1}, f\left(\sigma_{i-1}\right)\right)$ dengan sumbu $x$, dapat dihitung menggunakan persamaan (6)

Langkah 4: Menghitung $\left|e_{r}\right|$ dengan persamaan (7)

Langkah 5: Melakukan pengecekan:

(i) Jika $\left|e_{r}\right|<e_{t o l}$, maka iterasi selesai dengan $\sigma_{i}$ sebagai solusi $\sigma$ dari fungsi volatilitas $f(\sigma)$

(ii) Jika $\left|e_{r}\right|>e_{t o l}, \quad$ maka kembali ke langkah 1.
b.Penyelesaian menggunakan metode Secant

Langkah 1: Tetapkan hampiran awal $\sigma_{i-1}$ dan $\sigma_{i}, \quad e_{t o l}=10^{-5}$, max_iter $=100$.

Langkah 2: Mengitung nilai $f\left(\sigma_{i-1}\right)$ dan $f\left(\sigma_{i}\right)$

Langkah 3: Menentukan hampiran baru $\sigma_{i+1}$ dengan persamaan (8)

Langkah 4: Menghitung $\left|e_{r}\right|$ dengan persamaan (7)

Langkah 5: Melakukan pengecekan

(i) Jika $\left|e_{r}\right|<e_{t o l}$, maka iterasi selesai dengan $\sigma_{i+1}$ sebagai solusi $\sigma$ dari fungsi volatilitas $f(\sigma)$

(ii) Jika $\quad\left|e_{r}\right|>e_{t o l}$, maka kembali ke langkah 1 dengan menjadikan $\sigma_{i}$ sebagai $\sigma_{i-1}$ dan $\sigma_{i+1}$ sebagai $\sigma_{i}$.

c. Penyelesaian menggunakan metode Bisection

Langkah 1: Tetapkan hampiran awal $\sigma_{i-1}$ dan $\sigma_{i}, \quad e_{\text {tol }}=10^{-5}$, max_iter $=100$.

Langkah 2: Hitung nilai $f\left(\sigma_{i-1}\right)$ dan $f\left(\sigma_{i}\right)$.

Langkah 3: Memeriksa bahwa fungsi berubah tanda sepanjang interval $\left[\sigma_{i-1}, \sigma_{i}\right]$, ini dapat diperiksa dengan: $f\left(\sigma_{i-1}\right) f\left(\sigma_{i}\right)<0 . \quad$ Jika terpenuhi, hampiran awal dapat digunakan untuk iterasi berikutnya, namun jika tidak terpenuhi, pilih hampiran awal baru.

Langkah 4: Hampiran ketiga $\sigma_{i+1}$ dapat ditentukan menggunakan persamaan (9).

Langkah 5: Hitung nilai $f\left(\sigma_{i+1}\right)$

Langkah 6: Lakukan evaluasi sebagai berikut untuk menentukan di dalam subinterval mana akar fungsi terletak:

(i) Jika $f\left(\sigma_{i-1}\right) f\left(\sigma_{i+1}\right)<0$, maka $\sigma_{i}=\sigma_{i+1}$ 
(ii) Jika $f\left(\sigma_{i-1}\right) f\left(\sigma_{i+1}\right)>0$, maka $\sigma_{i-1}=\sigma_{i+1}$

Langkah 7: Menghitung $\left|e_{r}\right|$ dengan persamaan (7)

Langkah 8: Melakukan pengecekan.

(i) Jika $\left|e_{r}\right|<e_{t o l}$, dengan $i=1,2, \ldots, n$, maka iterasi selesai dengan $\sigma_{i+1}$ sebagai solusi $\sigma$ dari fungsi volatilitas $f(\sigma)$

(ii) Jika $\left|e_{r}\right|>e_{t o l}$, dengan $i=1,2, \ldots, n$, maka kembali ke langkah 4.

4. Membandingkan nilai taksiran Implied Volatility, kecepatan iterasi, serta membandingkan keakuratan masingmasing metode dengan membandingkan nilai error relatif $\left|e_{r}\right|$ dari masing-masing metode.

\section{HASIL DAN PEMBAHASAN}

Fungsi volatilitas dapat didefinisikan sebagai

$$
\begin{aligned}
f(\sigma)= & C_{o b s}-\left(S_{t} N\left(d_{1}\right)\right. \\
& \left.-K e^{-r(T-t)} N\left(d_{2}\right)\right)
\end{aligned}
$$

atau

$$
f(\sigma)=C_{o b s}-C_{B S}(\sigma)
$$

adalah kontinu dan memiliki turunan sebagai berikut:

$$
\begin{aligned}
f^{\prime}(\sigma) & =-\frac{\partial C_{B S}(\sigma)}{\partial \sigma} \\
& =-S_{t} \sqrt{T-t} \frac{1}{\sqrt{2 \pi}} e^{-\frac{d_{1}^{2}}{2}}
\end{aligned}
$$

adalah kontinu.

Teorema Eksistensi dan Ketunggalan (Waluya [5]), "Misalkan $f$ dan $\partial f / \partial \sigma$ kontinu, maka solusinya ada dan tunggal". Dalam hal ini, diperoleh bahwa $f(\sigma)$ dan $\frac{\partial f(\sigma)}{\partial \sigma}$ kontinu, maka Teorema Eksistensi dan Ketunggalan terpenuhi, yaitu terdapat solusi tunggal dari persamaan (11).

Tabel 1 Iterasi dengan Menggunakan Metode Newton-Raphson

\begin{tabular}{|l|l|c|c|c|c|}
\hline$i$ & $\sigma_{i-1}$ & $f\left(\sigma_{i-1}\right)$ & $f^{\prime}\left(\sigma_{i-1}\right)$ & $\sigma_{i}$ & $\left|e_{r}\right|$ \\
\hline 1 & 0.060000 & 0.055815 & -6.529788 & 0.068548 & $1.246985 \mathrm{e}-001$ \\
\hline 2 & 0.068548 & -0.002051 & -6.984392 & 0.068254 & $4.301345 \mathrm{e}-003$ \\
\hline 3 & 0.068254 & -0.000002 & -6.971129 & 0.068254 & $4.084282 \mathrm{e}-006$ \\
\hline
\end{tabular}

Tabel 2 Iterasi dengan Menggunakan Metode Secant

\begin{tabular}{|c|c|r|r|r|r|c|}
\hline$i$ & $\sigma_{i-1}$ & $f\left(\sigma_{i-1)}\right.$ & $\sigma_{i}$ & $f\left(\sigma_{i}\right)$ & $\sigma_{i+1}$ & $\left|e_{r}\right|$ \\
\hline 1 & 0.060000 & 0.055815 & 0.100000 & -0.237620 & 0.067609 & $4.791029 \mathrm{e}-001$ \\
\hline 2 & 0.100000 & -0.237620 & 0.067609 & 0.004490 & 0.068209 & $8.806070 \mathrm{e}-003$ \\
\hline 3 & 0.067609 & 0.004490 & 0.068209 & 0.000312 & 0.068254 & $6.568799 \mathrm{e}-004$ \\
\hline 4 & 0.068209 & 0.000312 & 0.068254 & -0.000001 & 0.068254 & $1.393661 \mathrm{e}-006$ \\
\hline
\end{tabular}


Tabel 3 Iterasi dengan Menggunakan Metode Bisection

\begin{tabular}{|c|c|c|r|r|r|r|c|}
\hline$i$ & $\sigma_{i-1}$ & $f\left(\sigma_{i-1}\right)$ & $\sigma_{i}$ & $f\left(\sigma_{i}\right)$ & $\sigma_{i+1}$ & $f\left(\sigma_{i+1}\right)$ & $\left|e_{r}\right|$ \\
\hline 1 & 0.060000 & 0.055815 & 0.100000 & -0.237620 & 0.080000 & -0.084613 & $2.500000 \mathrm{e}-001$ \\
\hline 2 & 0.060000 & 0.055815 & 0.080000 & -0.084613 & 0.070000 & -0.012240 & $1.428571 \mathrm{e}-001$ \\
\hline 3 & 0.060000 & 0.055815 & 0.070000 & -0.012240 & 0.065000 & 0.022433 & $7.692308 \mathrm{e}-002$ \\
\hline 4 & 0.065000 & 0.022433 & 0.070000 & -0.012240 & 0.067500 & 0.005243 & $3.703704 \mathrm{e}-002$ \\
\hline 5 & 0.067500 & 0.005243 & 0.070000 & -0.012240 & 0.068750 & -0.003464 & $1.818182 \mathrm{e}-002$ \\
\hline 6 & 0.067500 & 0.005243 & 0.068750 & -0.003464 & 0.068125 & 0.000899 & $9.174312 \mathrm{e}-003$ \\
\hline 7 & 0.068125 & 0.000899 & 0.068750 & -0.003464 & 0.068438 & -0.001280 & $4.566210 \mathrm{e}-003$ \\
\hline 8 & 0.068125 & 0.000899 & 0.068438 & -0.001280 & 0.068281 & -0.000190 & $2.288330 \mathrm{e}-003$ \\
\hline 9 & 0.068125 & 0.000899 & 0.068281 & -0.000190 & 0.068203 & 0.000354 & $1.145475 \mathrm{e}-003$ \\
\hline 10 & 0.068203 & 0.000354 & 0.068281 & -0.000190 & 0.068242 & 0.000082 & $5.724098 \mathrm{e}-004$ \\
\hline 11 & 0.068242 & 0.000082 & 0.068281 & -0.000190 & 0.068262 & -0.000054 & $2.861230 \mathrm{e}-004$ \\
\hline 12 & 0.068242 & 0.000082 & 0.068262 & -0.000054 & 0.068252 & 0.000014 & $1.430820 \mathrm{e}-004$ \\
\hline 13 & 0.068252 & 0.000014 & 0.068262 & -0.000054 & 0.068257 & -0.000020 & $7.153588 \mathrm{e}-005$ \\
\hline 14 & 0.068252 & 0.000014 & 0.068257 & -0.000020 & 0.068254 & -0.000003 & $3.576922 \mathrm{e}-005$ \\
\hline 15 & 0.068252 & 0.000014 & 0.068254 & -0.000003 & 0.068253 & 0.000005 & $1.788493 \mathrm{e}-005$ \\
\hline 16 & 0.068253 & 0.000005 & 0.068254 & -0.000003 & 0.068254 & 0.000001 & $8.942384 \mathrm{e}-006$ \\
\hline
\end{tabular}

Tabel 4 Perbandingan Nilai Volatilitas, Error Relatif dan Kecepatan Iterasi dari Metode NewtonRaphson, Metode Secant dan Metode Bisection

\begin{tabular}{|l|r|r|r|}
\hline \multirow{2}{*}{} & \multicolumn{3}{|c|}{ Metode } \\
\cline { 2 - 4 } & \multicolumn{1}{|c|}{ Newton-Raphson } & \multicolumn{1}{|c|}{ Secant } & \multicolumn{1}{c|}{ Bisection } \\
\hline Implied Volatility $(\sigma)$ & $6,8254 \%$ & $6,8254 \%$ & $6,8254 \%$ \\
\hline Berhenti pada Iterasi ke- $i$ & 3 & 4 & 16 \\
\hline Error Relatif $\left|e_{r}\right|$ & $4,084282 \mathrm{e}-006$ & $1,393661 \mathrm{e}-006$ & $8,942384 \mathrm{e}-006$ \\
\hline
\end{tabular}

Berdasarkan Tabel 1, dapat ditarik kesimpulan bahwa nilai volatilitas diperoleh pada iterasi ke-3 yaitu dengan nilai $\sigma=$ $0,068254=6,8254 \%$ dan error relatif $\left|e_{r}\right|=4,084282 \mathrm{e}-006$. Berdasarkan Tabel 2, dapat ditarik kesimpulan bahwa nilai volatilitas diperoleh pada iterasi ke-4 yaitu dengan nilai $\sigma=0,068254=6,8254 \%$ dan error relatif $\left|e_{r}\right|=1,393661 \mathrm{e}-006$. Berdasarkan Tabel 3, dapat ditarik kesimpulan bahwa nilai volatilitas diperoleh pada iterasi ke-16 yaitu dengan nilai $\sigma=0,068254=$ $6,8254 \%$ dan error relatif $\left|e_{r}\right|=8,942384 \mathrm{e}-$ 006. Berdasarkan Tabel 4 diperoleh hasil simulasi menggunakan metode NewtonRaphson, metode Secant, dan metode Bisection dengan nilai Implied Volatility yang sama, yaitu $6,8254 \%$. Simulasi berhenti secara berturutturut pada iterasi ke-3; 4; 16 dengan nilai error relatif secara berturut-turut sebesar 4,084282e006; 1,393661e-006; 8,942384e-006. Implied Volatility yang diperoleh menggunakan metode Newton-Raphson, Secant, dan Bisection memiliki nilai yang lebih besar dari nilai Implied Volatility di pasar modal, yaitu sebesar $6,25 \%$. Berdasarkan pemaparan pada bab II, Implied Volatility yang tinggi mengakibatkan harga opsi menjadi mahal dan berlaku sebaliknya.

Berdasarkan tabel 1, 2, dan 3, diperoleh bahwa pada iterasi ke-3 metode NewtonRaphson, metode Secant dan metode Bisection secara berturut-turut memiliki error relatif sebesar 4,084282e-006; 6,568799e-004; 7,692308e-002. Dalam hal ini, metode NewtonRaphson memiliki error relatif terkecil pada iterasi ke-3 yaitu sebesar 4,084282e-006. Artinya, metode Newton-Raphson lebih akurat 
dibandingkan metode Secant dan metode Bisection. Dengan demikian, dapat disimpulkan bahwa metode Newton-Raphson adalah metode terbaik dalam menaksir Implied Volatility saham, karena metode Newton-Raphson konvergen paling cepat dan paling akurat dibandingkan metode Secant dan metode Bisection.

\section{KESIMPULAN DAN SARAN}

\section{A. Kesimpulan}

Berdasarkan hasil dan pembahasan yang telah diuraikan pada bab sebelumnya, estimasi Implied Volatility saham menggunakan metode Newton-Raphson, metode Secant dan metode Bisection dengan hampiran awal 0,06 dan hampiran kedua 0,1 untuk metode Secant dan metode Bisection memiliki perolehan nilai Implied Volatility yang sama, yaitu 6,8254\% yang nilainya lebih tinggi dari Implied Volatility di pasar modal, yaitu $6,25 \%$. Implied Volatility yang tinggi akan mengakibatkan harga opsi menjadi mahal. Metode NewtonRaphson lebih cepat konvergen, yaitu pada iterasi ke-3 dan menghasilkan nilai error relatif yang lebih kecil dari pada metode Secant dan metode Bisection. Dengan demikian dapat disimpulkan bahwa metode Newton-Raphson adalah metode terbaik dalam menaksir Implied Volatility saham, karena metode ini konvergen paling cepat dan paling akurat dibandingkan metode Secant dan metode Bisection.

\section{B. Saran}

Metode Newton-Raphson, Secant dan Bisection tidak dapat memberikan keputusan di dalam pasar modal, metode ini hanya dapat menaksir nilai Implied Volatility, yang dapat digunakan sebagai gambaran/acuan dalam melakukan suatu keputusan. Implied Volatility juga dapat ditaksir menggunakan metode GARCH (conditional volatility), Monte Carlo dengan simulasi, dan Model Heston dengan stokastik volatilitas.

\section{DAFTAR PUSTAKA}

[1] Black, F. \& Scholes, M., 1973. The Pricing of Options and Corporate Liabilities. The Journal of Political Economy, 81(3), PP. 637-659.

[2] Dharmawan, Komang \& Widana, I Nyoman., 2011. Aplikasi Algoritma Biseksi dan Newon-Raphson dalam Menaksir Nilai Volatilitas Implied. Jurnal Matematika Vol. 2 No. 1, Desember 2011. ISSN: 1693-1394.

[3] Lee, Roger. W., 2002. Implied Volatility: Statics, Dynamics, and Probabilitic Interpretation. Recant Advances in Applied Probability 2005, pp. 241-268.

[4] Mathews, John H., 1992. Numerical Methods. For Mathematics, Science, and Engineering. Second edition. USA: Prentice-Hall International, Inc.

[5] Waluya, St. Budi., 2006. Buku Ajar Persamaan Diferensial, 21-23. 